\title{
Power Quality Improvement using Passive shunt filters, TCR and TSC combination
}

\author{
${ }^{1}$ Vinaypreet, ${ }^{2}$ Dr. A.K. Ghai, ${ }^{3}$ Prof. Devesh Bindal, \\ ${ }^{1}$ Dept. of Electrical Engineering, Sri Sukhmani Institute of Engineering \& Technology,Derabassi, Punjab, \\ ${ }^{2,3}$ Professors, Sri Sukhmani Institute of Engineering \& Technology,Derabassi, Punjab
}

\begin{abstract}
In this thesis Power Quality Improvement is examined using Passive shunt filter, TCR and TSC combination. Today's electric power systems are connected to many non-linear loads. The characteristics of these non-linear loads inevitably change the sinusoidal nature of the a.c. power current, resulting in the flow of harmonic current in the a.c. power system. Use of shunt passive filters in the reduction of harmonics offers the advantages of more simplicity, high reliability, high efficiency and low cost. The uncontrolled ac-dc converter suffers from operating problems of poor power factor, injection of harmonics into the ac mains, variations in dc link voltage of input ac supply, equipment overheating due to harmonic current absorption, voltage distortion due to the voltage drop caused by harmonic currents flowing through system impedances etc. The combinations of passive filters with TCR and TSC are designed and analyzed to improve the power quality at ac mains. This scheme has resulted in improved power quality with overall reduced rating of passive components used in front end ac-dc converters with R-L load.
\end{abstract}

\section{INTRODUCTION}

Today's electric power systems are connected to many non-linear loads. These include static power converters, arc discharge devices, electronic control equipment by way of semiconductor devices, saturated magnetic devices and rotating machines. Nonlinear loads produce harmonic currents that can travel to other locations in the power system and eventually back to the source. Harmonics in power systems result in increased heating in the equipment and conductors, misfiring in variable speed drives, and torque pulsations in motors.

Total harmonic distortion, or THD is a common measurement of the level of harmonic distortion present in power systems. THD is defined as the ratio of total harmonics to the value at fundamental frequency.

$$
\mathrm{THD}=\frac{\sqrt{V_{2}^{2}+V_{3}^{2}+V_{4}^{2}+\cdots+V_{n}^{2}}}{V_{1}}
$$

Where $V_{n}$ is the RMS voltage of $n$th harmonic and $n=1$ is the fundamental frequency. The significant harmonic frequency currents generated in power conversion equipment can be stated as:

$$
n=k q \pm 1
$$

where,

$n$ is the significant harmonic frequency,

$k$ is any positive integer $(1,2,3$, etc.), and

$q$ is the pulse number of the power conversion equipment which is the number of power pulses that are in one complete sequence of power conversion. For example, a three-phase full wave bridge rectifier has six power pulses and therefore has a pulse number of 6 . With sixpulse power conversion equipment, the following significant harmonics may be generated:

For $k=1, n=(1 \times 6) \pm 1=5^{\text {th }}$ and 7 th harmonics. For $k=2, n=(2 \times 6) \pm 1=11^{\text {th }}$ and 13th harmonics.[1]

\section{DEFINITION OF POWER QUALITY:}

- The IEEE Standard Dictionary of Electrical and Electronics defines Power Quality as "the concept of powering and grounding sensitive electronic equipment in a manner that is suitable to the operation of that equipment."

- Power Quality is "the provision of voltages and system design so that the user of electric power can utilize electric energy from the distribution system successfully without interference or interruption.’'[2]

\section{INTRODUCTION TO PASSIVE FILTERS}

The use of passive filter in the mitigation of harmonic in 3 phase system use the utilizing with thyristor controlled reactor \& thyristor switched capacitor is the most significant development in the field of harmonic distortion mitigation. Passive filter are used for the mitigation of harmonic component in six pulse converter with RL load \& also provide the reactive power compensation in the system to improve the power quality so by mean of this power 
filter helps the system by two means one is to improve the system power quality \& improve reactive power problem so reduced the need of capacitor for supplying extra needed KVAR. $[3,4]$

For current source type of harmonic producing loads, generally, passive shunt filters are recommended. The performance of these filter depends mainly on the system source impedance, as these filter act as sinks for the harmonic currents. [5] On the other hand, for voltage source type harmonic producing loads, the use of the series passive filters is recommended. These filters block the flow of harmonic current into ac mains, by providing high impedance path at certain harmonic frequencies for which the filter is tuned. It is observed that both these configuration fail to meet the IEEE standard 519 guidelines under varying load conditions. A novel configuration of passive hybrid filter (a combination of passive shunt and passive series filter) is designed and developed for power quality improvement.

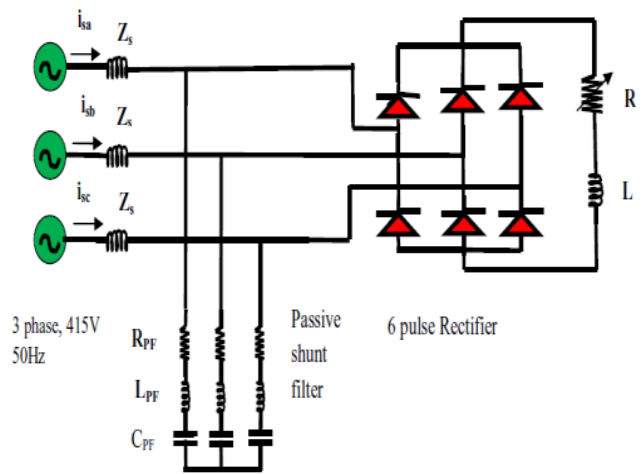

Fig 1 Schematic diagram of an ac-dc converter with R-L load and passive shunt filter at input

\section{THYRISTOR-CONTROLLED REACTOR (TCR)}

A TCR is one of the most important building blocks of thyristor-based SVCs. Although it can be used alone, it is more often employed in conjunction with fixed or thyristor switched capacitors to provide rapid, continuous control of reactive power over the entire selected lagging-toleading range. This device is essentially a variable reactor that can adjust its reactive power consumption. The adjustment is realized through the firing angles of thyristors that normally operate in partial conducting states, and thereby produce harmonics. Poor selection of firing angles can lead to increase in the amount of effective harmonic production of the TCR.[6] A thyristor controlled reactor is usually a threephase assembly, normally connected in a delta arrangement to provide partial cancellation of harmonics. For higher order harmonics, harmonic filters are connected in parallel with the TCR. The filters provide capacitive reactive power which partly offsets the inductive reactive power provided by the TCR.

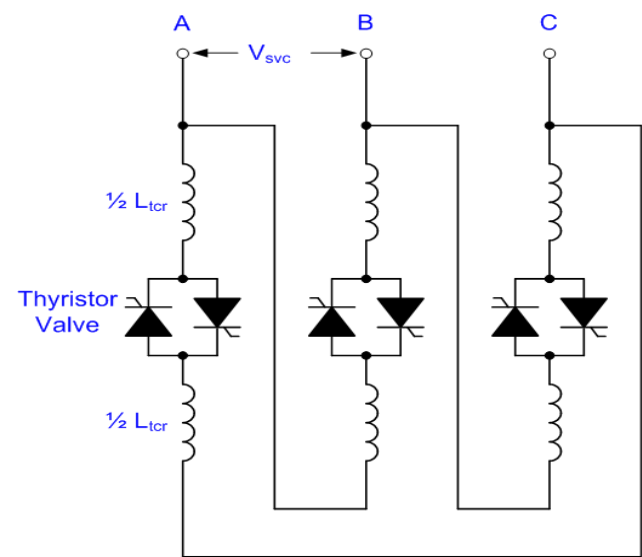

Fig 2 Thyristor controlled reactor circuit

\section{THYRISTOR SWITCHED CAPACITOR (TSC)}

The thyristor switched capacitor is an important component of a Static VAR Compensator (SVC), where it is often used in conjunction with a thyristor controlled reactor (TCR). A TSC is usually a three-phase assembly, connected either in a delta or a star arrangement. Unlike the TCR, a TSC generates no harmonics and so requires no filtering. For this reason, some SVCs have been built with only TSCs. Although a disadvantage is that the reactive power output can only be varied in steps. Continuously variable reactive power output is only possible where the SVC contains a TCR or another variable element such as a STATCOM.

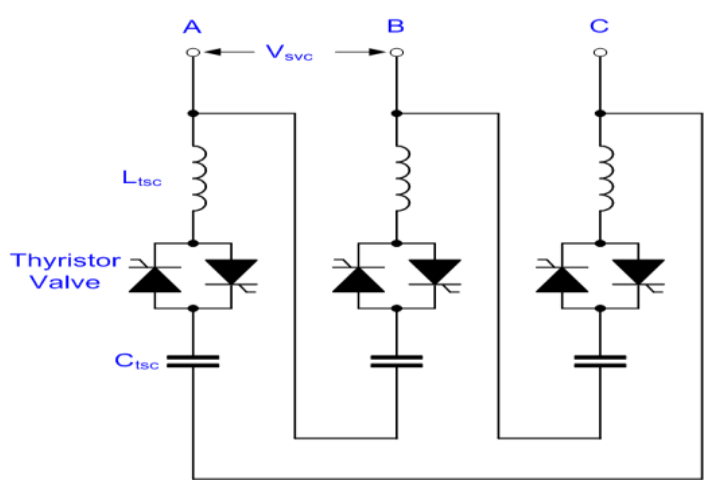

Fig 3 Thyristor switched capacitor circuit

It consists of capacitor in series with bidirectional thyristor switch. It is supplied from a ac voltage source. The analysis of the current transients after closing the switch brings two cases: 
1. The capacitor voltage is not equal to the supply voltage when the thyristors are fired. Immediately after closing the switch, a current of infinite magnitude flows and charges the capacitor to the supply voltage in an infinitely short time. The switch realized by the thyristor cannot withstand this stress and would fail.

2. The capacitor voltage is equal to the supply voltage when the thyristors are fired. The current will jump immediately to the value of the steadystate current. Although the magnitude of the current does not exceed the steady-state values, the thyristor have an upper limit of $d i / d t$ that they can withstand during the firing process. Here $d i / d t$ is infinite, and the thyristor switch will again fail.

\section{TCR-TSC COMBINATION}

The TCR-TSC comprises usually n-series of TSC and single TCR that are connected in parallel. The capacitor can be switched in discrete steps, whereas continuous control within the reactive power span of each step is provided by TCR. As the size of TCR is small the harmonic generation is substantially reduced. The TSC branches are tuned with series reactor to different dominant harmonic frequencies. The main motivations in developing TCR_TSC were for enhancing the operational flexibility of the compensator during large disturbances and for reducing the steady-state losses.

What particularly aggravate the problem in which severe voltage swings are experienced and followed by the load rejection. But TCR-TSC can quickly operate to disconnect all the capacitor from the compensator, producing resonant oscillations. The proposed configuration for passive shunt filter with TCR and TSC.

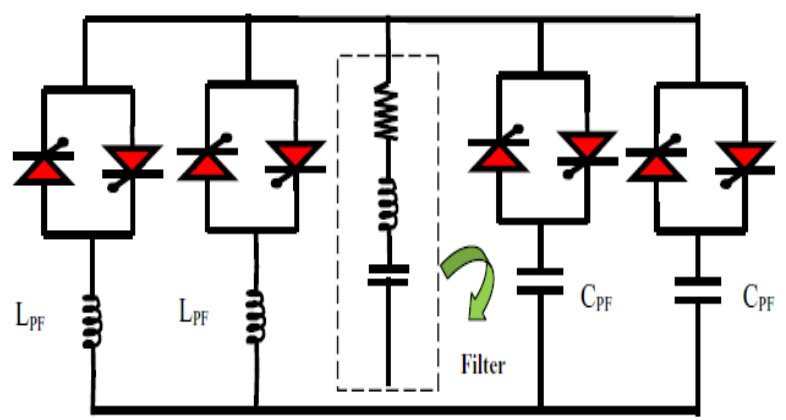

Fig 5 Circuit diagram of TCR TSC Combination

\section{MATLAB BASED MODELING OF PASSIVE FILTER}

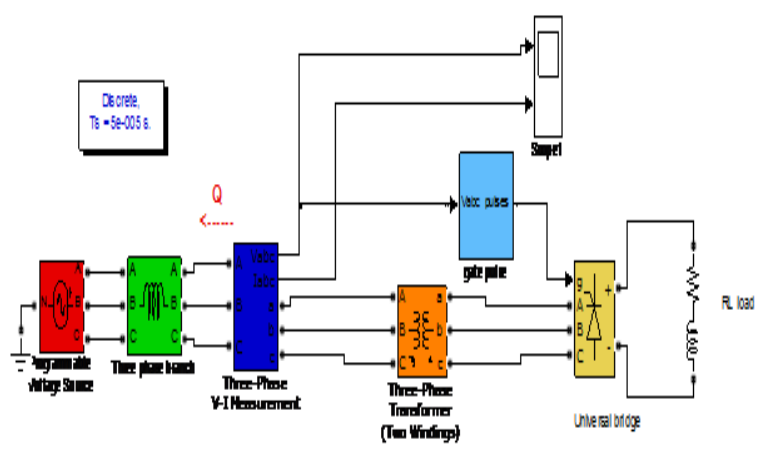

Fig 6 MATLAB based model of a six pulse ac-dc converter R-L load without passive shunt filter

Fig.7 shows the MATLAB model of a passive shunt filter based six pulse ac-dc converters with R-L load. Depending on the harmonic spectrum of the supply current, the passive filters designed are low pass filter tuned for 5th order harmonic frequency. The subsystem named shunt filter consists of 5th harmonic frequency. Based on the design carried out the filter component values are $\mathrm{L}=16 \mathrm{mH}, \mathrm{C}=25 \mu \mathrm{F}, \mathrm{R}=0.83 \Omega$.

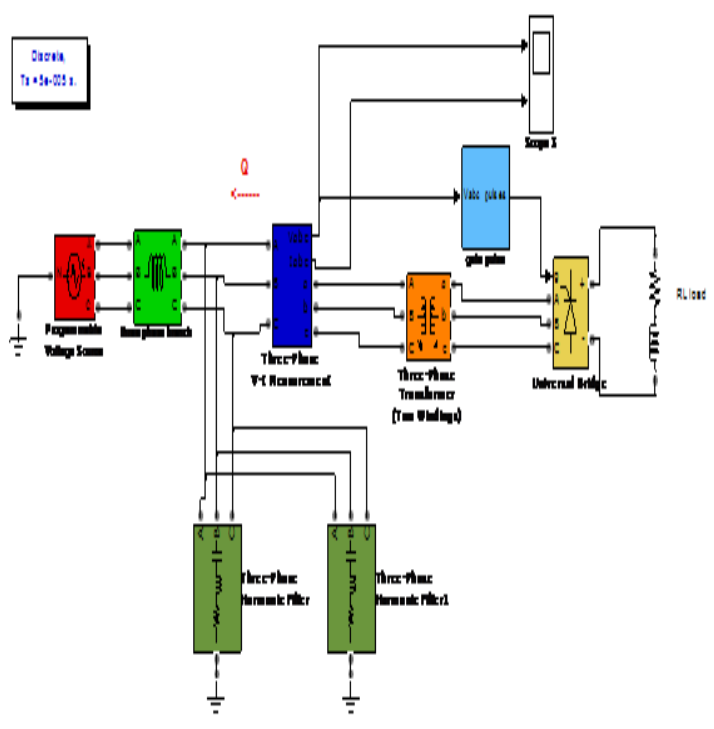

Fig 7 MATLAB based model of a six pulse ac-dc converter R-L load with passive shunt filter 


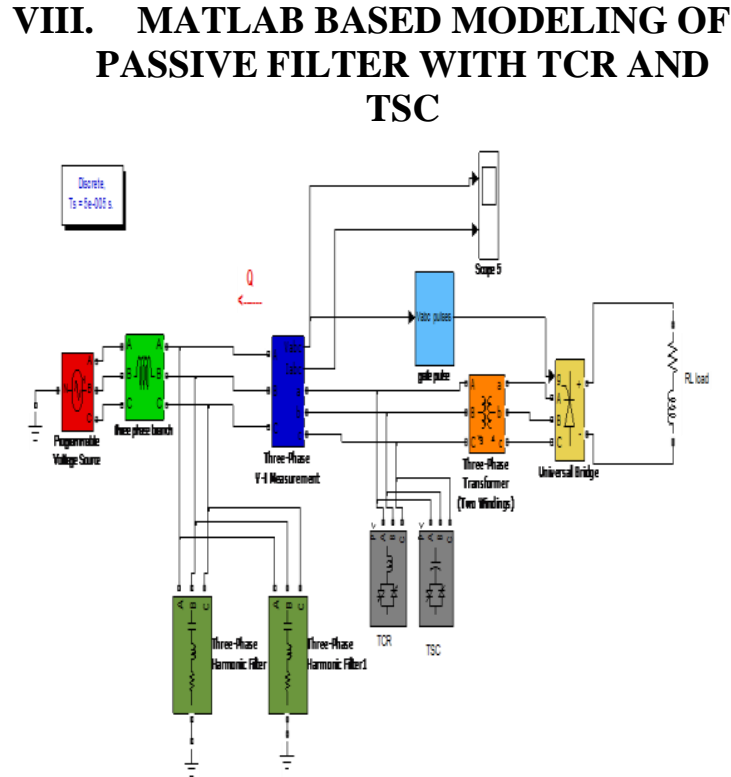

Fig 8 MATLAB based model of a six pulse ac-dc converter R-L load with passive filter TCR and TSC combination

\section{RESULTS AND DISCUSSIONS}

IX.I Performance of basic ac-dc Converter with R-L Load

Case A: First simulation is done on ac-dc converter which don't have filters or combination of TCRTSC connected to it. A $5^{\text {th }}$ and a $7^{\text {th }}$ harmonics are injected into the circuit for the time period of 0 $0.3 \mathrm{sec}$. Total simulation time of the model is $0.5 \mathrm{sec}$. Acc to fig, the first waveform is of Supply voltage $\mathrm{v} / \mathrm{s}$ time and second waveform is of source current $\mathrm{v} / \mathrm{s}$ time. The waveforms are highly distorted for the time harmonics are injected i.e. during 0-0.3. After that waveforms are normal.
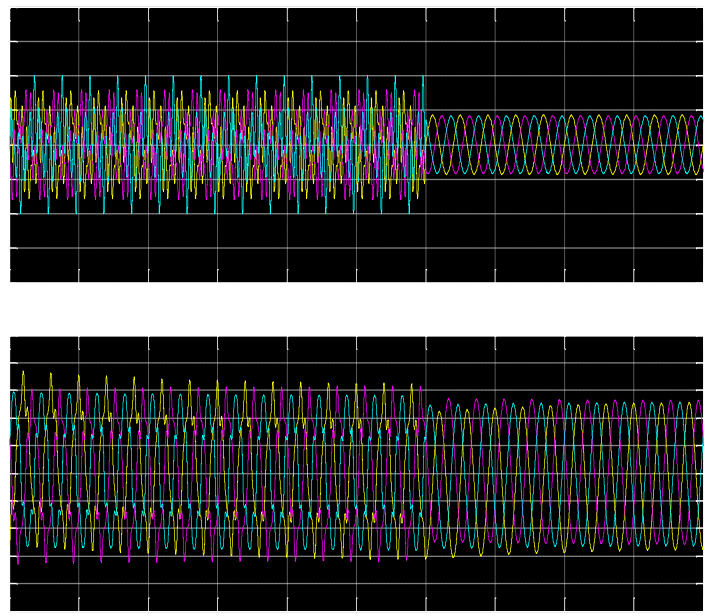

Fig 9 AC mains voltage and current response in simulation for converter with R-L load without passive shunt filter

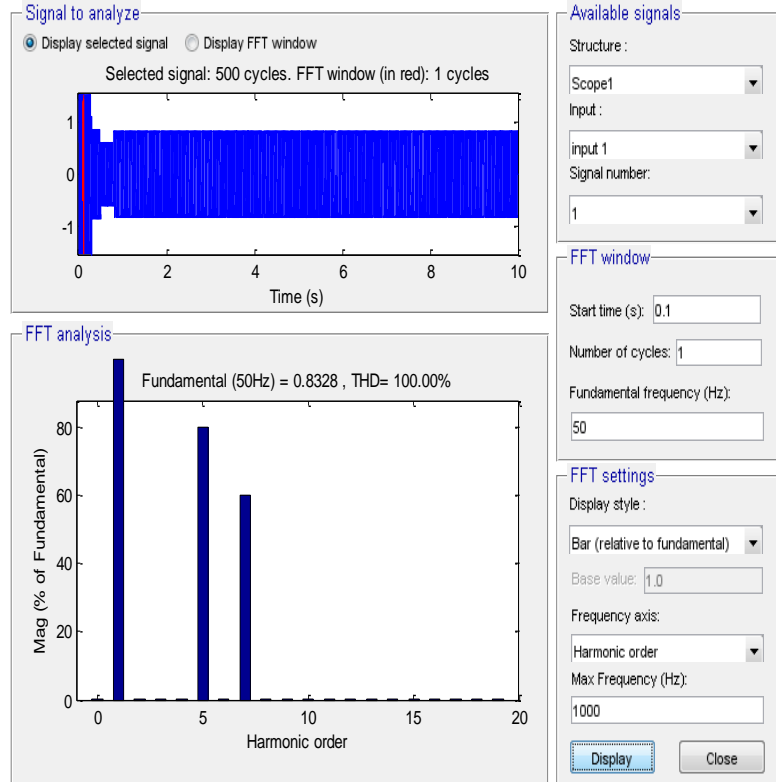

Fig $10 \mathrm{AC}$ mains voltage response with \% THD in simulation for converter with R-L load without passive filter

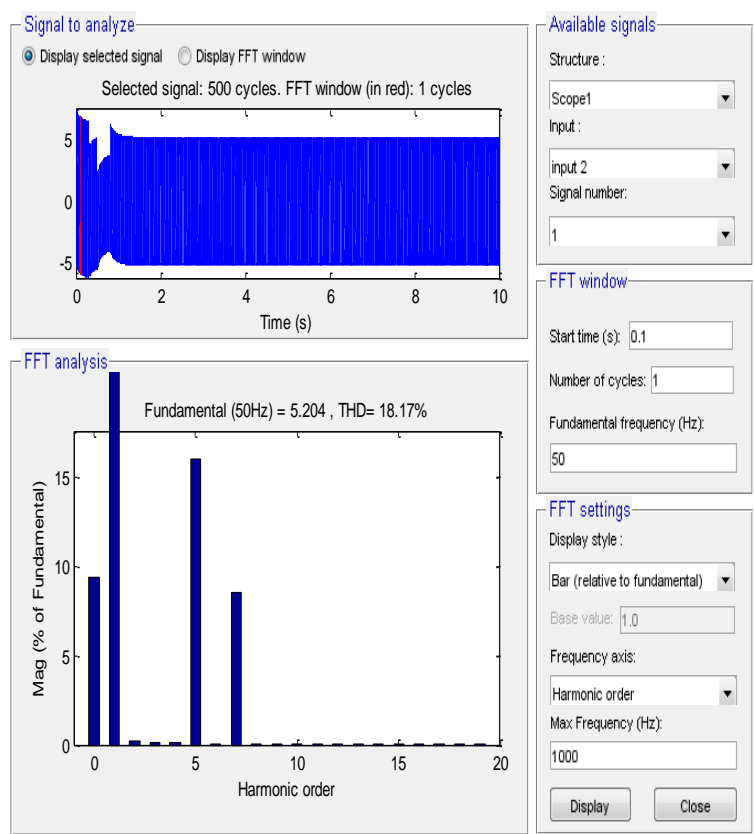

Fig 11 AC mains current response with \% THD in simulation for converter with R-L load without passive shunt filter

\section{PERFORMANCE OF PASSIVE SHUNT FILTER BASED AC-DC CONVERTER WITH R-L LOAD}

Case B: Second simulation is done on ac-dc converter having passive shunt filter connected to it. As seen in fig, by connecting passive shunt filters tuned at harmonic frequencies the waveform of voltage and current are improved to large extent 

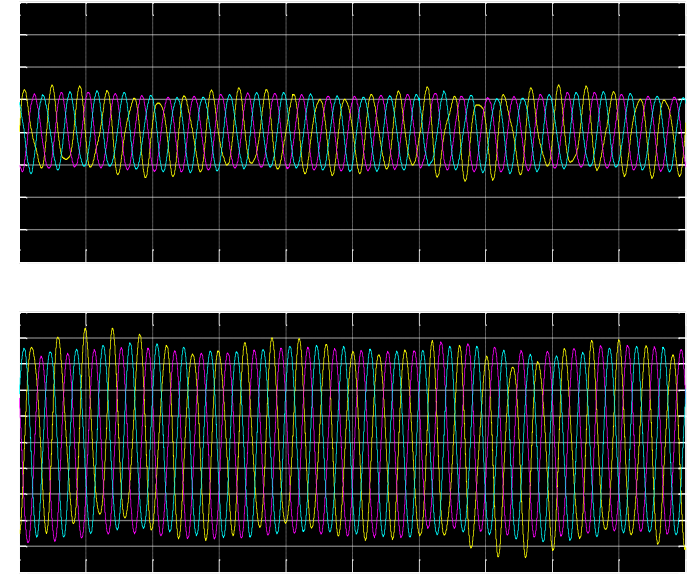

Fig12 AC mains voltage and current response in simulation for converter with R-L load with passive shunt filter

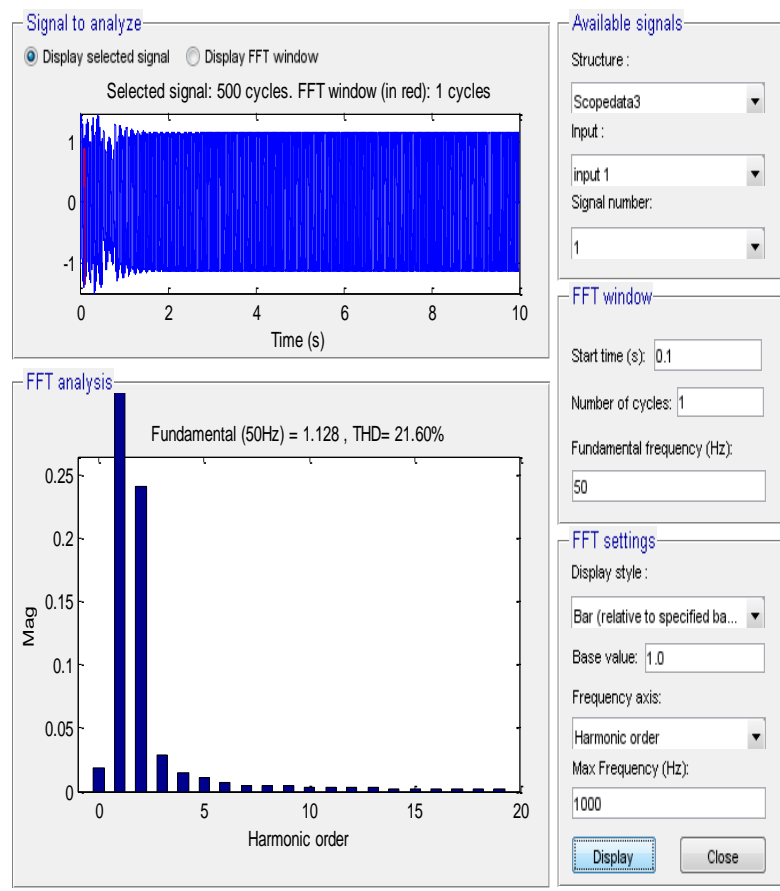

Fig 13 AC mains voltage response with \% THD in simulation for converter with R-L load with passive filter

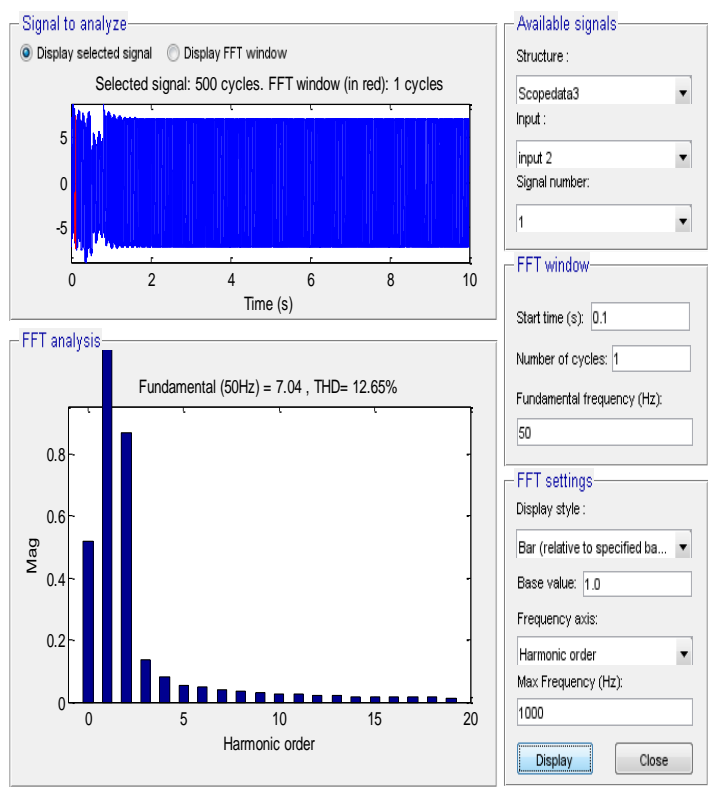

Fig 15 AC mains current response with \% THD in simulation for converter with R-L load with passive filter

\section{PERFORMANCE OF AC-DC CONVERTER HAVING FILTER, TCR AND TSC WITH R-L LOAD}

Case C: Third simulation is done on converter containing filter, TCR and TSC combination. As seen in fig, waveforms of source voltage and current $\mathrm{v} / \mathrm{s}$ time are very near to three phase sine waveform
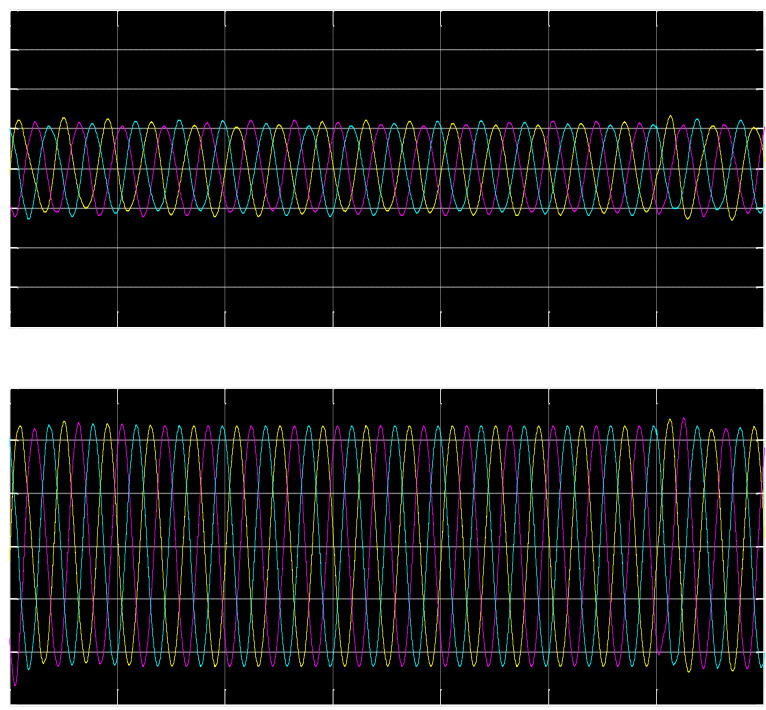

Fig 16 Voltage and current response of the ac-dc converter with passive filter, TCR and TSC combination 


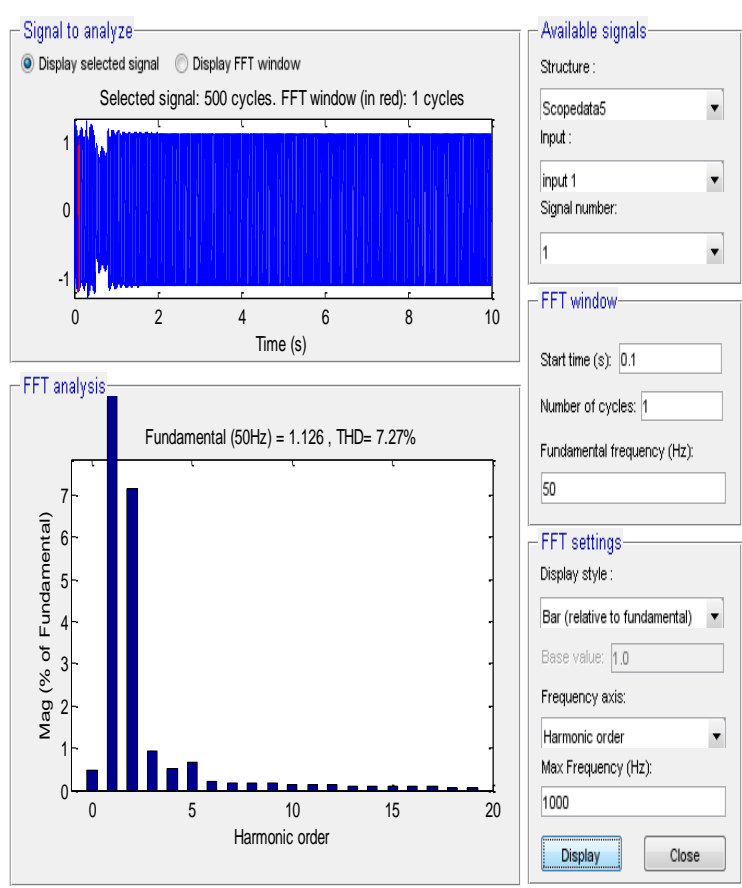

Fig17 Voltage response and THD of the ac-dc converter with passive filter, TCR and TSC Combination

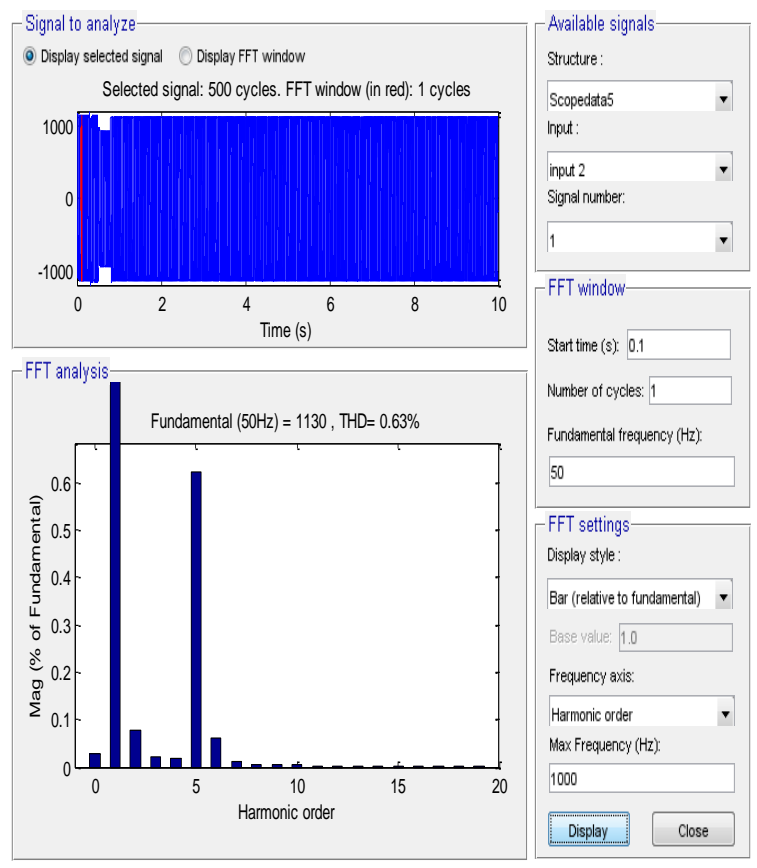

Fig18 Current response and THD of the ac-dc converter with passive filter, TCR and TSC combination

\section{COMPARISONS THD WITH DIFFERENT SCHEMES}

\begin{tabular}{|c|c|c|}
\hline $\begin{array}{c}\text { MATLAB } \\
\text { SIMULINK } \\
\text { MODEL }\end{array}$ & $\begin{array}{c}\text { VOLTAGE } \\
\text { THD } \%\end{array}$ & $\begin{array}{c}\text { CURRENT } \\
\text { THD } \%\end{array}$ \\
\hline $\begin{array}{c}\text { WITHOUT } \\
\text { FILTER }\end{array}$ & 100 & 18.17 \\
\hline WITH FILTER & 21.60 & 12.65 \\
\hline $\begin{array}{c}\text { WITH FILTER, } \\
\text { TCR AND TSC }\end{array}$ & 7.27 & 0.63 \\
\hline
\end{tabular}

\section{CONCLUSION}

- The effect of multiple harmonic sources can be investigated by applying the superposition principle.

- The system represented by linear models at each harmonic frequency.

- The precise evaluation of harmonic distortion must have accurate load modeling.

- Hence the TCR-TSC combination is better in SVC.

\section{REFERENCES}

[1]. N.G. Hingorani, "Introducing custom power", IEEE Spectrum, June, pp:41-48,1995.

[2]. C. Sankaran, "Power Quality", CRC Press 2002

[3]. Ray Arnold, “ Solutions to Power Quality Problems" power engineering journal 2003 pages 65-73.

[4]. A.M. Sharaf, Poerre Kreidi, "Power Quality enhancement and harmonic reduction using dynamic power filters", $7^{\text {th }}$ International Conference on Modeling and simulation of Electric Machines, Converters and Systems. August, 2002.

[5]. Kuldeep Kumar Srivastava, Saquib Shakil, Anand Vardhan Pandey, "Harmonics \& Its Mitigation Technique by Passive Shunt Filter," International Journal of Soft Computing and Engineering (IJSCE) ISSN: 2231-2307, Volume-3, Issue-2, May 2013.

[6]. Abdulkareem Mokif Obais, Dr. Jagadeesh Pasupuleti , "Harmonics Reduction of Thyristor Controlled Reactor with Minimal No Load Operating Losses," Canadian Journal on Electrical and Electronics Engineering Vol. 2, No. 7, July 2011. 2010. 